Research Article

\title{
Measurement of Annular Flow for Drilling Engineering by Electromagnetic Flowmeter Based on Double-Frequency Excitation
}

\author{
Liang Ge $\mathbb{D},{ }^{1,2}$ Yang He $\mathbb{D},{ }^{1}$ Guiyun Tian $\mathbb{D}^{3},{ }^{3}$ Guohui Wei $\mathbb{D},{ }^{1}$ Junaid Ahmed, ${ }^{4}$ \\ Hongxia Deng, ${ }^{1}$ and Qi Huang ${ }^{1}$ \\ ${ }^{1}$ College of Mechanical and Electronic Engineering, Southwest Petroleum University, Chengdu 610500, China \\ ${ }^{2}$ Key Laboratory of Oil and Gas Equipment, Ministry of Education, Chengdu 610500, China \\ ${ }^{3}$ School of Engineering, Newcastle University, Newcastle NE1 7RU, UK \\ ${ }^{4}$ Electrical Department, Sukkur IBA University, Sukkur 65200, Pakistan \\ Correspondence should be addressed to Guiyun Tian; g.y.tian@ncl.ac.uk
}

Received 5 May 2019; Revised 2 September 2019; Accepted 21 September 2019; Published 18 November 2019

Academic Editor: Everardo Vargas-Rodriguez

Copyright $\odot 2019$ Liang Ge et al. This is an open access article distributed under the Creative Commons Attribution License, which permits unrestricted use, distribution, and reproduction in any medium, provided the original work is properly cited.

\begin{abstract}
Using downhole annular electromagnetic flow measurement to obtain annular flow in real-time is a foundation of microflow control drilling technology. The existing annular flow electromagnetic measurement method based on low-frequency rectangular excitation is affected by slurry interference and formation fluid invasion, which results in large noise generated on the electrode output signal. These noise causes the instability of the flow measurement system output and lower accuracy. Double-frequency rectangular wave excitation has the advantages of excellent zero-point stability attributed to low-frequency rectangular wave excitation and fast response speed with great ability to suppress slurry interference. First, the double-frequency rectangular wave excitation for annular flow electromagnetic measurement is researched, and its corresponding electromagnetic induction signal process is investigated. In order to verify the feasibility of downhole annular electromagnetic flow measurement, a flow verification platform for comparison of standard and detected parameters is established for simulation experiment, and the ability to suppress slurry interference and response speed of the technology in downhole slurry flow measurement are analyzed. The test results show that the downhole annular electromagnetic flow measurement based on double-frequency rectangular wave excitation can not only satisfy the requirements of regular electromagnetic flow measurement but also suppress the annular slurry interference effectively.
\end{abstract}

\section{Introduction}

With the expansion of oil and gas exploration field, the drilling security problems of deep-sea environment, complex strata, shallow gas layer, and matured oil fields caused by strata high pressure due to water injection are becoming severe. Blowout is caused by uncontrollable spouting of the formation fluid due to its higher pressure than the downhole space. Overflow, the precursor of a blowout, is formation fluid invasion into downhole space when the bottom pressure cannot balance the strata pressure. If it is not found in time, the drilling fluid contamination and tool erosion will be caused, and the blowout, in particular, will lead to serious accident and harm. Downhole microflow control drilling technology can deal with overflow and blowout effectively in narrow secure density window drilling, and using downhole annular flow measurement to obtain the annular flow information in real-time is the core of realizing downhole microflow control drilling [1].

Aiming at the special downhole environment in oil and gas while drilling, the limitation of borehole space to measurement system size, as well as the effect of downhole pressure, temperature, multiphased fluids containing oil and gas bubbles and solid particles plus the variations of downhole fluid domain on measurement, instrument measurement accuracy, and response characteristics, needs comprehensive 
consideration. In the literature, the researchers proposed different methods and solutions such as acoustics [2-4], pressure difference $[5,6]$, and electromagnetics $[7,8]$ for the downhole annular flow measurement while drilling. These methods have achieved some successes but have some problems. For instance, numerous theoretical and practical problems of non-Newtonian fluid measurement containing many solid particles remain unsolved in the acoustics method; throttling components obstructing the flowing of measured media are used in the pressure difference method, leading to the loss of part of the pressure as well as congestion at the throttling spots, and bringing severe hidden dangers and lower annular flow accuracy; the electromagnetic method is easily affected by slurry interference and formation fluid invasion, with large noise generated on the electrode output signal, which results in the instability of the annular electromagnetic flow measurement system. The problems of the electromagnetic method in the downhole annular process are studied in this paper.

The existing electromagnetic flowmeter mostly measures the flow of ordinary conductive fluids based on low-frequency rectangular wave excitation. Although lowfrequency rectangular wave excitation has excellent zeropoint stability, this technology is characterized by a lot of limitations, such as large jumps while measuring slurry fluid, which results in the extremely unstable output of the electromagnetic flow sensor and lowers accuracy. Meanwhile, when the flow changes rapidly, low-frequency rectangular wave excitation is not suitable due to its slow response speed. However, improving the excitation frequency of the electromagnetic flowmeter only, though workable to solve the problem of response speed and suppresses the slurry noise, affects the zero-point stability greatly and therefore leads to lower accuracy. With the continuous expansion of the application field of the electromagnetic flowmeter and development of excitation technology, the advanced excitation technology represented by doublefrequency rectangular wave excitation appears [9]. Based on the theory of this technology, the downhole annular flow measurement technology with double-frequency wave excitation not only has excellent zero-point stability of lowfrequency rectangular wave excitation but also has fast response speed and great ability to suppress slurry interference of the high-frequency one.

Kumemori Kenichi first developed the theory for doublefrequency rectangular wave excitation in 1988. He offered the basic flow chart of double-frequency rectangular wave excitation and proposed the advantages of zero-point stability, fast response, slurry noise suppression, little polarization interference, high measurement accuracy, etc., but without putting out specific details [9-12]. Ichiro Wada developed the double-frequency time division excitation electromagnetic flow measurement system in 1992. Low-frequency square wave excitation and the high-frequency one worked in turns and flow signals of high and low frequencies were demodulated, respectively. Then, the weights of lowfrequency and high-frequency results were selected according to the signal fluctuation rate, and the weights were added before output [13]. Xu et al. proposed a double-frequency excitation control method based on the exchange of high and low voltage power in 2012. This method solved the problems of low excitation frequency of instability, long slurry measurement delay, and large fluctuation [14]. Liu and Gong investigated a time multiplexing double-frequency rectangular excitation in 2013. Excitation was carried out through the multiplexing of high-frequency double value rectangular wave and a low-frequency one, and the hardware process was used to realize flow signal processing [15]. Zhao designed the measurement system of oil and gas double-phased flow rate based on a double-frequency rectangular wave excitation control [16].

In the drilling process, annular flow measurement is quite crucial. Lots of slurry noises are contained in the measured signals because the fluid is slurry in the annulus, and the zero stability is poor. These shortcomings lead to great difficulties in measurement. In this work, we proposed an annular electromagnetic flow measurement technology for drilling engineering by electromagnetic flowmeter based on doublefrequency excitation. This technology can not only satisfy the requirements of regular electromagnetic flow measurement but also suppress the annular slurry interference effectively and meet the needs of rapid overflow detection. It is worth emphasizing that there is no literature reporting the use of the electromagnetic flow system based on double-frequency excitation to measure the flow rate of annular drilling fluid to our knowledge.

The remainder of this paper is organized as follows. Section 2 introduces the double-frequency rectangular wave excitation for annular flow electromagnetic measurement and its corresponding electromagnetic induction signal process. Section 3 describes the realization of the annular electromagnetic flow system based on double-frequency excitation and contains the results of the empirical analysis. Section 4 concludes.

\section{Theory of Annular Electromagnetic Flowmeter Based on Double- Frequency Excitation}

2.1. Model of Downhole Annular Flow Electromagnetic Measurement Principle. In 1970, according to Shercliff [17], Bevir proposed a three-dimensional weight vector calculation method, which made the electromagnetic flowmeter develop rapidly. The electromagnetic flowmeter also starts with Maxwell's equations. According to Maxwell's equations,

$$
\left\{\begin{array}{l}
\nabla \times \vec{H}=\vec{j}+\frac{\partial \vec{D}}{\partial \vec{t}}, \\
\nabla \times \vec{E}=-\frac{\partial \vec{B}}{\partial \vec{t}}, \\
\nabla \cdot \vec{B}=0, \\
\nabla \cdot \vec{D}=\rho .
\end{array}\right.
$$


The constitutional relationship between the dynamic conductive medium satisfies

$$
\begin{aligned}
& \vec{D}=\varepsilon \vec{E}, \\
& \vec{B}=\mu \vec{H} \\
& \vec{j}=\sigma(\vec{E}+\vec{v} \times \vec{B}) .
\end{aligned}
$$

To simplify the question, it is proposed that the fluid magnetic permeability is even and equal to that in the vacuum space (nonmagnetic fluid); fluid conductivity is uniform and satisfies the Ohm Law Equation: $\vec{j}=\sigma(\vec{E}+\vec{v} \times \vec{B})$, where $\sigma$ is the fluid conductivity; the electric displacement can be neglected. Ignoring the induced electric field generated by the time-varying magnetic field $(\vec{E}=-\nabla \varphi)$, other effects like the Hall effect and the thermoelectric effect are excluded.

The differential form of basic equations can be conducted from Maxwell equations:

$$
\nabla^{2} \varphi=\nabla \cdot(\vec{v} \times \vec{B})=\vec{B} \cdot(\nabla \times \vec{v})-\vec{v} \cdot(\nabla \times \vec{B})
$$

Assume that $\varphi$ and $\vec{j}$ denote the electric potential generated when the fluids are flowing. $\varphi_{v}$ and $\overrightarrow{j_{v}}$ are, respectively, the virtual electric potential and current density vector generated by unit current flowing through the electrodes when the fluids are static. Then, assuming that $\mathrm{A}$ and $\mathrm{B}$ are electrodes made of good conductors, $\tau$ is the space volume. $\vec{j}$ and $\overrightarrow{j_{v}}$ are both zero on the pipe shell except for the electrodes. The following equation (4) can be obtained according to Green's Second Theory through the above conditions $[17,18]$, and the annular electromagnetic flowmeter is a special case out of the traditional ones, which still satisfies the following formula:

$$
U=\int_{\tau} W \cdot \vec{v} d \tau
$$

where $W=\vec{B} \times \overrightarrow{j_{v}}$. Here, $U$ is the potential between two electrodes, $W$ is the weight function vector, $\vec{v}$ is the velocity of the annular flow, and $\vec{B}$ is the magnetic flux vector. Suppose the fluid is static and the current density vector of the unit current flowing from positive to negative, $\tau$ is the integration of the annular volume.

In the traditional electromagnetic measurement system [19], the coil excitation system is installed outside the circular measurement pipe, with the electrodes on two sides of the pipe. Such installation can satisfy the need for flow measurement inside the traditional circular pipeline, while the excitation and signal extraction are both relatively easier. However, two conditions need realizing as for electromagnetic detection, which is similar to the downhole annular channel flow. One is the magnetic field generated on the

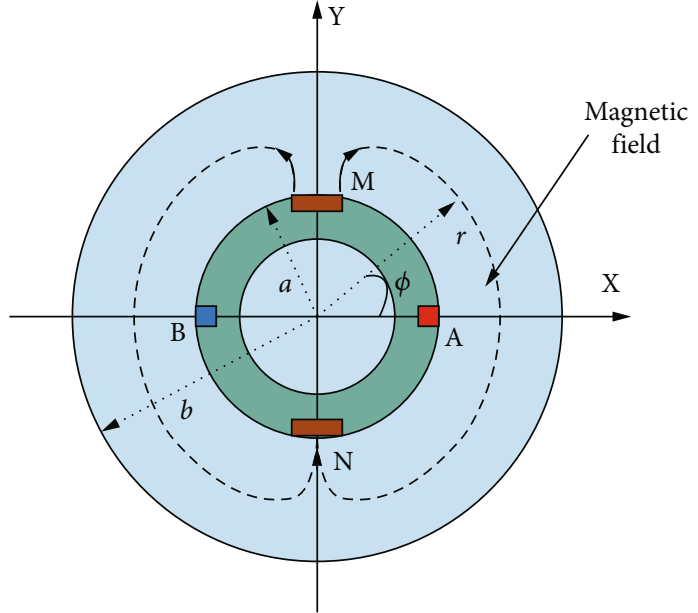

FIgURE 1: Schematic diagram of the annular two-electrode flow electromagnetic measurement system.

annular channel, the other is the electrodes installed annularly to realize the signal extraction.

In order to satisfy the two conditions mentioned above, an annular channel flow electromagnetic detection model is proposed, as shown in Figure 1. In this model, two coil excitation structures $\mathrm{M}$ and $\mathrm{N}$ are designed to generate the magnetic field in certain directions. A pair of electrodes A and $\mathrm{B}$ is installed in the annular channel outwards. The area in blue is the magnetic field. The flow cuts the magnetic line while flowing through the magnetic field, generating electromotive force between the electrodes, from which the electromagnetic induction signal can be extracted.

Generally, there is no electric power and a magnetic source inside the annular flow electromagnetic measurement system, so the electrical potential $\mathrm{G}$ and magnetic potential $\mathrm{F}$ within the flow area satisfy the Laplace equations:

$$
\begin{aligned}
& \nabla^{2} G=0, \\
& \nabla^{2} F=0,
\end{aligned}
$$

and the virtual current density $\vec{j}$ and magnetic flux vector $\vec{B}$ can be further denoted by

$$
\begin{aligned}
& \vec{j}=-\nabla G, \\
& \vec{B}=-\nabla F .
\end{aligned}
$$

In real applications, the annular flow velocity is measured. Therefore, the main goal of downhole annular flow electromagnetic measurement system research is to obtain the virtual current density $\vec{j}$ and magnetic flux vector $\vec{B}$.

To figure out $\vec{j}$ and $\vec{B}, \vec{B}$ is determined by the physical structure size and excitation current information of the coil for the downhole annular flow electromagnetic measurement. Discussions on $\vec{B}$ have been studied [8]. Only $\vec{j}$ of the downhole annular flow electromagnetic measurement 
system, which has basically been formed in structure and size, is analyzed here.

According to Figure 1, assume that the conductivity of the wellbore wall is far greater than that of the drilling fluid. Therefore, the wellbore wall can be seen as the ideal grounding conductor, and the boundary condition $\left.G\right|_{r=b}=0$ can be obtained. Since the point electrode can be expressed as $\left.(\partial G / \partial r)\right|_{\text {Electrode position }}=\delta(r) \delta(\phi) \delta(z) / r$, equation (7) can be obtained:

$$
\left\{\begin{array}{l}
\frac{\partial^{2} G}{\partial r^{2}}+\frac{1}{r} \frac{\partial G}{\partial r}+\frac{1}{r^{2}} \frac{\partial^{2} G}{\partial \phi^{2}}=0, \\
\left.G\right|_{r=b}=0 \\
\left.\frac{\partial G}{\partial r}\right|_{r=a}=\left\{\begin{array}{l}
\frac{\delta\left(\phi-\phi_{\mathrm{A}}\right)}{a}, \\
\frac{-\delta\left(\phi-\phi_{\mathrm{B}}\right)}{a},
\end{array}\right.
\end{array}\right.
$$

where $\phi_{\mathrm{A}}=0$ and $\phi_{\mathrm{B}}=\pi$ are the angular positions of electrodes $\mathrm{A}$ and $\mathrm{B}$.

Separation of variables is applied to solve the differential equations (7). So it can be obtained that

$\frac{\partial G}{\partial r}=D_{0} \frac{1}{r}+\sum_{n=1}^{\infty} n r^{-n-1}\left(C_{n} r^{2 n}-D_{n}\right)\left(A_{n} \sin n \phi+B_{n} \cos n \phi\right)$.

According to the boundary condition $G_{r=b}=0$, we have

$$
\begin{aligned}
& C_{0}=0, \\
& D_{0}=0, \\
& D_{n}=-C_{n} b^{2 n} .
\end{aligned}
$$

Therefore,

$$
\begin{aligned}
G & =\sum_{n=1}^{\infty} C_{n}\left(r^{n}-b^{2 n} r^{-n}\right)\left(A_{n} \sin n \phi+B_{n} \cos n \phi\right), \\
\frac{\partial G}{\partial r} & =\sum_{n=1}^{\infty} n r^{-n-1} C_{n}\left(r^{2 n}+b^{2 n}\right)\left(A_{n} \sin n \phi+B_{n} \cos n \phi\right) .
\end{aligned}
$$

Assume the angular position satisfies

$$
\begin{aligned}
\phi_{A} & =\theta+\frac{\pi}{2}, \\
\phi_{B} & =\theta-\frac{\pi}{2}, \\
& -\pi<\theta<\pi,
\end{aligned}
$$

where $\theta$ is the deviation from axis Y. The clockwise deviation is defined as negative, while counterclockwise as positive.
According to the boundary condition $\partial G /\left.\partial r\right|_{r=a}=$ $\delta\left(\phi-\phi_{A}\right) / a$,

$$
\begin{aligned}
A_{n} & =\frac{a^{n} \sin (n \theta+n(\pi / 2))}{n \pi C_{n}\left(a^{2 n}+b^{2 n}\right)}, \\
B_{n} & =\frac{a^{n} \cos (n \theta+n(\pi / 2))}{n \pi C_{n}\left(a^{2 n}+b^{2 n}\right)}, \\
G_{1}(r, \phi) & =\frac{1}{\pi} \sum_{n=1}^{\infty} \frac{(a / b)^{n}(r / b)^{n}-(a / r)^{n}}{n\left[(a / b)^{2 n}+1\right]} \cos n\left(\phi-\theta-\frac{\pi}{2}\right) .
\end{aligned}
$$

Similarly, according to the boundary condition $\partial G /\left.\partial r\right|_{r=a}=-\delta\left(\phi-\phi_{B}\right) / a$,

$$
\begin{aligned}
A_{n} & =-\frac{a^{n} \sin (n \theta-n(\pi / 2))}{n \pi C_{n}\left(a^{2 n}+b^{2 n}\right)}, \\
B_{n} & =-\frac{a^{n} \cos (n \theta-n(\pi / 2))}{n \pi C_{n}\left(a^{2 n}+b^{2 n}\right)}, \\
G_{2}(r, \phi) & =-\frac{1}{\pi} \sum_{n=1}^{\infty} \frac{(a / b)^{n}(r / b)^{n}-(a / r)^{n}}{n\left[(a / b)^{2 n}+1\right]} \cos n\left(\phi-\theta+\frac{\pi}{2}\right) .
\end{aligned}
$$

Linear superimposition of two equations constitutes a solution which satisfies the boundary condition; therefore,

$$
\begin{aligned}
G & =G_{1}+G_{2}=\frac{1}{\pi} \sum_{n=1}^{\infty} \frac{(a / b)^{n}(r / b)^{n}-(a / r)^{n}}{n\left[(a / b)^{2 n}+1\right]}\left[\cos n\left(\phi-\theta-\frac{\pi}{2}\right)\right. \\
& \left.-\cos n\left(\phi-\theta+\frac{\pi}{2}\right)\right] .
\end{aligned}
$$

By simplifying (14), equation (15) is obtained:

$$
G(r, \phi)=\frac{2}{\pi} \sum_{n=1,3,5}^{\infty} \frac{(a / b)^{n}(r / b)^{n}-(a / r)^{n}}{n\left[(a / b)^{2 n}+1\right]} \cos n\left(\phi-\theta-\frac{\pi}{2}\right) .
$$

Assume that $\tau$ and $R$ satisfy

$$
\begin{aligned}
\tau & =\frac{a}{b}, \\
R & =\frac{r}{b} .
\end{aligned}
$$

By simplifying (15), we have the virtual current vector

$$
G=\frac{2}{\pi} \sum_{n=1,3,5}^{\infty} \frac{R^{n}-R^{-n}}{n\left[\tau^{n}+\tau^{-n}\right]} \cos n\left(\phi-\theta-\frac{\pi}{2}\right)
$$




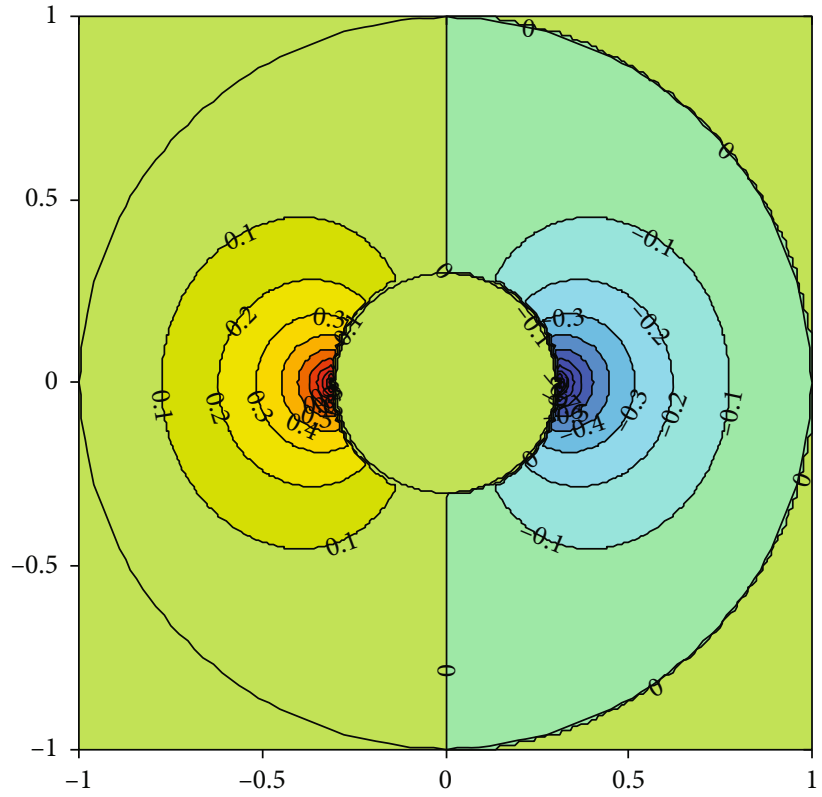

(a) Virtual current potential

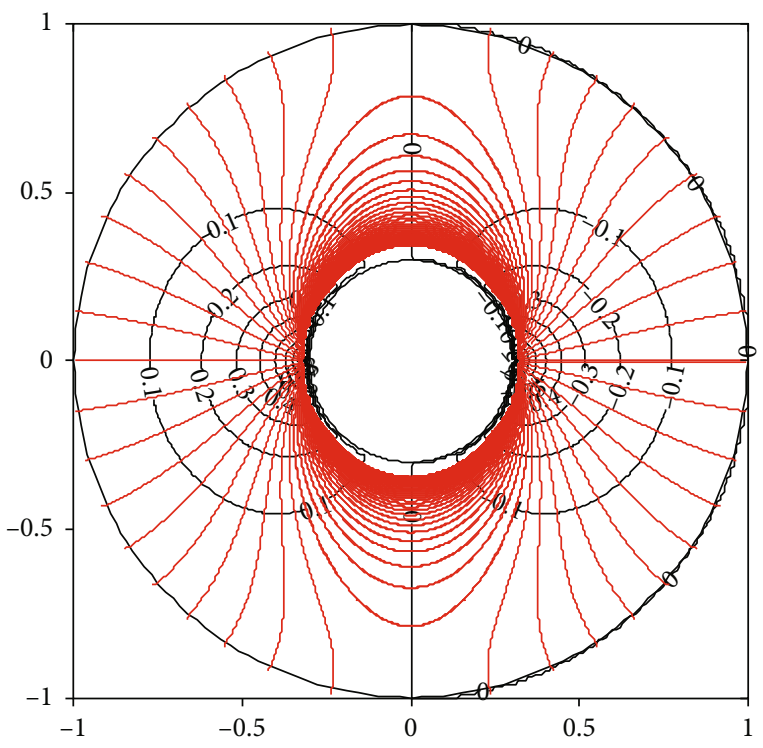

(b) Virtual current potential contour and virtual current vector streamline

FIgURE 2: Virtual current potential contour when $\tau=0.3$ and $\theta=0$.

When $\tau=0.3$ and $\theta=0$, a virtual current potential as in Figure 2(a) is painted according to equation (17). Figure 2(b) includes a virtual current potential contour and virtual current vector streamline graph, painted based on equations (17) and (18).

The virtual current density vector is

$$
\boldsymbol{j}=-\nabla G=-\left(\boldsymbol{e}_{r} \frac{\partial G}{\partial r}+\boldsymbol{e}_{\phi} \frac{1}{r} \frac{\partial G}{\partial \phi}\right),
$$

where

$j_{r}=-\frac{\partial G}{\partial r}=-\frac{2}{\pi} \sum_{n=1,3,5}^{\infty} \frac{(a / b)^{n+1}(r / b)^{n-1}+(a / r)^{n+1}}{a\left[(a / b)^{2 n}+1\right]} \cos n\left(\phi-\theta-\frac{\pi}{2}\right)$,

$j_{\phi}=\frac{2}{\pi b} \sum_{n=1,3,5}^{\infty} \frac{R^{n-1}-R^{-n-1}}{\tau^{n}+\tau^{-n}} \sin n\left(\phi-\theta-\frac{\pi}{2}\right)$.

Take $\tau=0.3, b=1$, and $\theta=0$, and according to equation (19), the virtual current component $j_{r}$ contour is painted, as shown in Figure 3(a). Meanwhile, based on equation (20), the virtual current component $j_{\phi}$ is portrayed in Figure 3(b). As shown in Figure 3, the virtual current values around the signal detection electrode are relatively large and vary greatly at the boundary, which is distributed symmetrically.

2.2. Double-Frequency Rectangular Excitation. The excitation signal of the downhole annular flow measurement is crucial, which directly determines the stability and reliability of the system output signal. The excitation signal is generally generated before the flow signal of the electromagnetic flow mea- surement system. Therefore, the performance of the excitation circuit is directly related to zero-point stability and anti-interference ability of the system. The downhole annular flow electromagnetic measurement with lowfrequency rectangular wave excitation has great zeropoint stability but unstable electromagnetic flow sensor output affected by slurry interference. In particular when the fluid intrudes into the downhole formation rapidly, the response of the measurement system is relatively slow, not satisfying the measurement with rapid flow variation. Therefore, the double-frequency excitation principle is applied to realize the annular flow electromagnetic measurement system.

The analysis of double-frequency rectangular control process is as follows: as shown in Figure 4, unipolar square wave signals of $6.25 \mathrm{~Hz}$ and $75 \mathrm{~Hz}$ are generated by the EPWM2A and EPWM3A ports of the enhanced PWM output model. These signals are then sent to the channel controlling port of multicircuited analog switches A and B, in order to control the channel selection. Finally, the input values of the operational amplifier are exchanged among positive, zero, and negative, to realize the control to double-frequency wave excitation of the coil.

\subsection{Demodulation of Electrode Output Signal under Double- Frequency Rectangular Wave Excitation}

2.3.1. Principle of Amplitude Demodulation. In order to study the technology of the electrode output signal process of downhole annular fluid flow electrode flow, the electrode output signal can be simplified as the superposition of flow signal, differential interference signal, and working frequency interference signal. As shown in Figure 5, through highfrequency sampling time sequence, the second part of the 


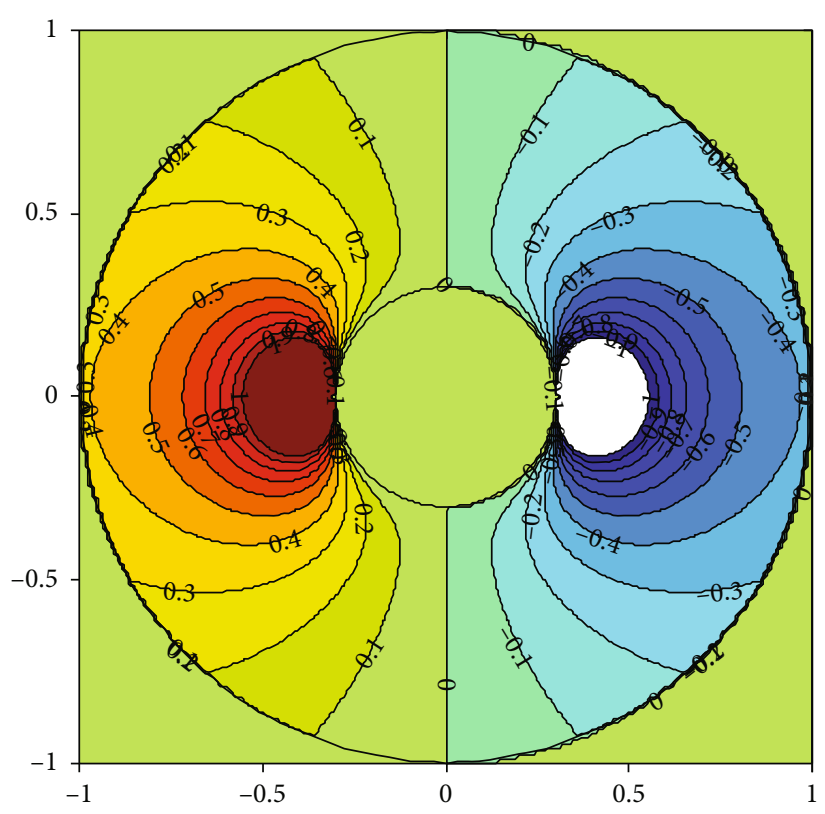

(a) Virtual current component $j_{r}$

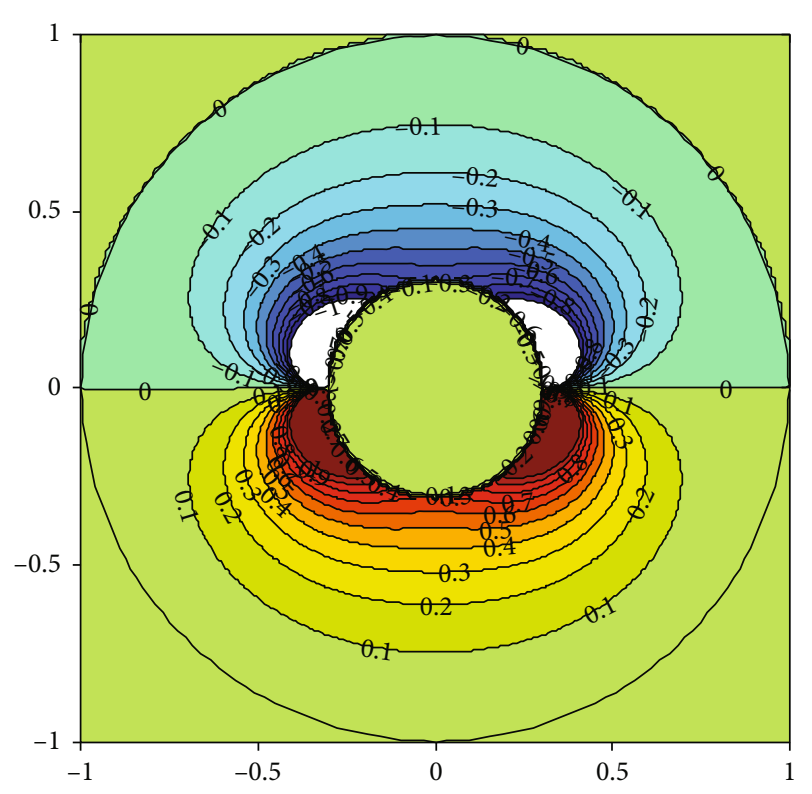

(b) Virtual current component $j_{\phi}$

Figure 3: Virtual current contour when $\tau=0.3, b=1$, and $\theta=0$.

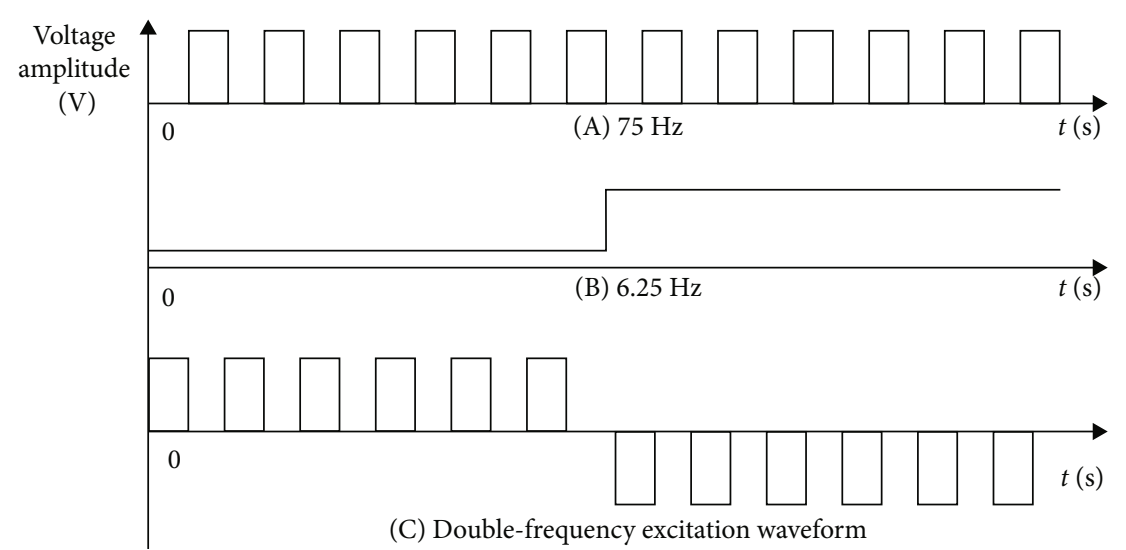

FIgURE 4: Control sequence of double-frequency rectangular wave excitation.

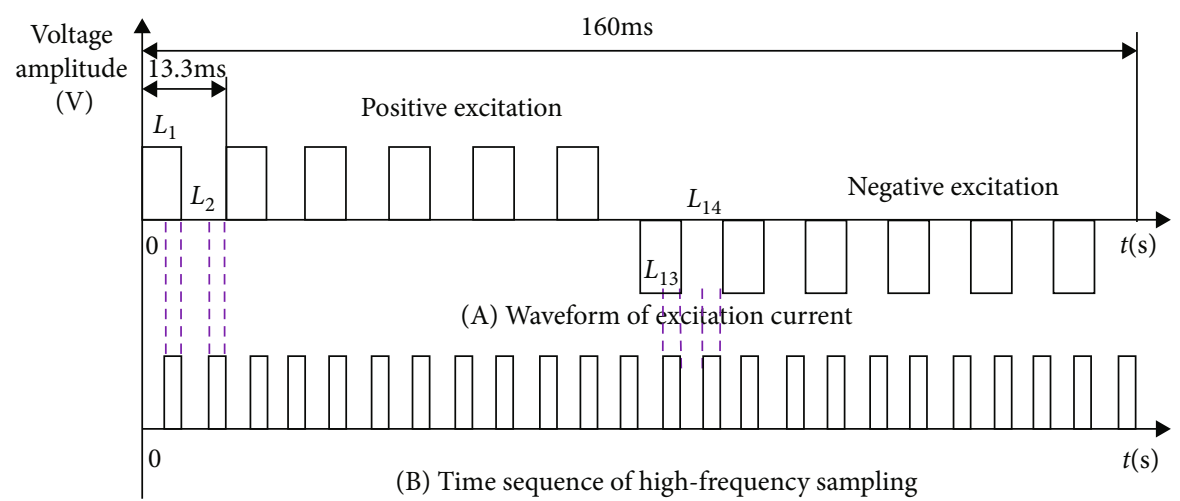

FIGURE 5: Sampling sequence of the output signal of double-frequency rectangular wave excitation. 


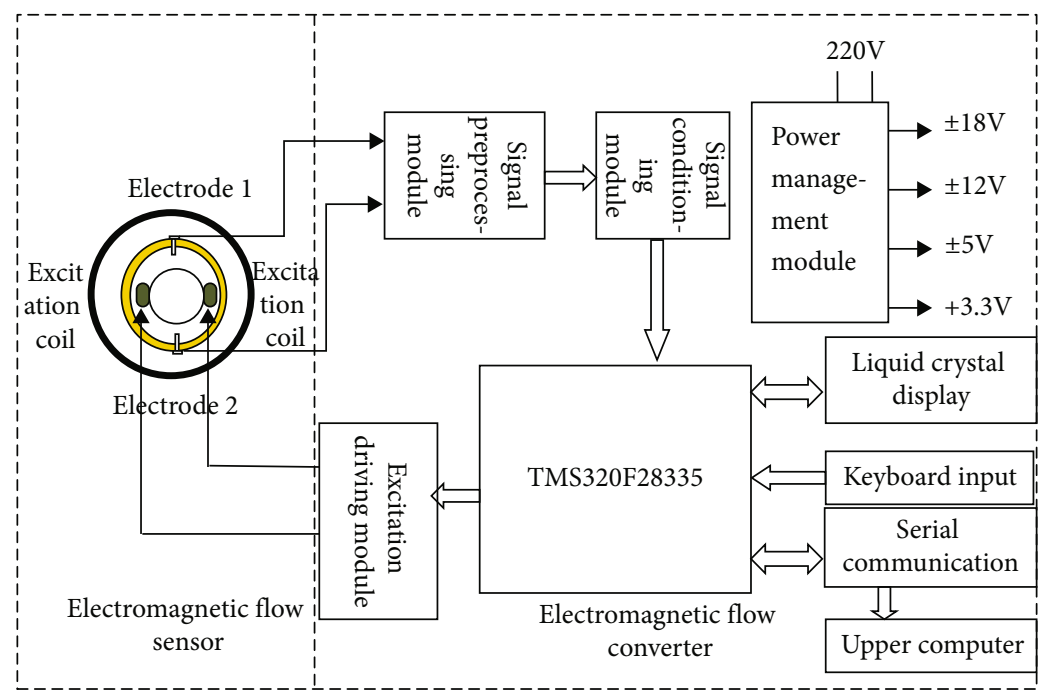

FIgURE 6: Framework of the electromagnetic annular flowmeter measurement system with double-frequency excitation.

electrode output signal half period is collected under highfrequency excitation as the accordance of flow calculation. Affected by the interference signal, the data in the latter part of the electrode output signal half period is relatively stable and can reflect flow information in the annular space. Assuming that the data segments obtained in the first highfrequency period of positive excitation are $L_{1}$ and $L_{2}$, those in negative excitation are $L_{13}$ and $L_{14}$ similarly. Suppose $k$ points are collected in each high-frequency half period, as shown in

$$
\begin{aligned}
L_{1} & =\left[L_{1}(1), L_{1}(2), \cdots, L_{1}(k)\right], \\
L_{2} & =\left[L_{2}(1), L_{2}(2), \cdots L_{2}(k)\right], \\
L_{13} & =\left[L_{13}(1), L_{13}(2), \cdots, L_{13}(k)\right], \\
L_{14} & =\left[L_{14}(1), L_{14}(2), \cdots, L_{14}(k)\right] .
\end{aligned}
$$

In the double-frequency rectangular wave excitation studied in this paper, the low-frequency excitation frequency is $6.25 \mathrm{~Hz}$, and the amplitude and phase of the working interference imposed on $L_{1}(i), L_{2}(i), L_{13}(i)$, and $L_{14}(i)$ are almost consistent, where $1 \leq i \leq k$. By pairwise subtraction of $L_{1}(i)$ and $L_{13}(i), L_{2}(i)$, and $L_{14}(i)$, with other interferences not considered, the working interference can be eliminated, and lowfrequency direct current drift suppressed. The specific principle of the method is shown in

$$
\text { Awi }=\frac{\sum_{i=1}^{k}\left[L_{1}(i)-L_{2}(i)+L_{14}(i)-L_{13}(i)\right]}{k}
$$

where $L_{1}(i), L_{2}(i), L_{13}(i)$, and $L_{14}(i)$ are data in the latter stable segment in each half period of the electrode output signal under positive and negative high-frequency excitations. Awi is the amplitude demodulation result of the electrode output flow signal under double-frequency rectangular excitation.
2.3.2. Annular Flow Demodulation Algorithm. High-frequency sampling, with a half period of $6.66 \mathrm{~ms}$, is used for $75 \mathrm{~Hz}$ square wave signal. Due to the differential interference, the stable part of the electrode output signal is very narrow, with only a limited number of points where sampling is workable. Through the practical test, the time period in the stable part of the electrode output signal is around $1.2 \mathrm{~ms}$. The sampling frequency is set as $27 \mathrm{kHz}$, namely, with 32 data points collected every half period as effective data, recorded as $D_{L}(1: 32)$.

To reduce the effect of other noises in the environment, a 16-point moving average filtering algorithm is performed to 32 data points first, written as $D_{L}^{i}$, as shown in

$$
\begin{aligned}
& D_{L_{1}}^{1}=\sum_{i=1}^{16} D_{L_{1}}(i) \times \frac{1}{16}, \\
& D_{L_{1}}^{2}=\sum_{i=2}^{17} D_{L_{1}}(i) \times \frac{1}{16}, \\
& \ldots \\
& D_{L_{1}}^{16}=\sum_{i=16}^{32} D_{L_{1}}(i) \times \frac{1}{16} .
\end{aligned}
$$

Similarly, the second half period processing result is $D_{L_{2}}^{1}, \cdots, D_{L_{2}}^{16}$, the $13^{\text {th }}$ period one is $D_{L_{13}}^{1}, \cdots, D_{L_{13}}^{16}$, and the $14^{\text {th }}$ period is $D_{L_{14}}^{1}, \cdots, D_{L_{14}}^{16}$. According to the principle of amplitude demodulation, the value Awi is shown in

$$
\begin{aligned}
& \operatorname{Awi}(L)^{1}=D_{L_{1}}^{1}-D_{L_{2}}^{1}+D_{L_{14}}^{1}-D_{L_{13}}^{1}, \\
& \operatorname{Awi}(L)^{2}=D_{L_{1}}^{2}-D_{L_{2}}^{2}+D_{L_{14}}^{2}-D_{L_{13}}^{2}, \\
& \ldots \\
& \operatorname{Awi}(L)^{16}=D_{L_{1}}^{16}-D_{L_{2}}^{16}+D_{L_{14}}^{16}-D_{L_{13}}^{16} .
\end{aligned}
$$




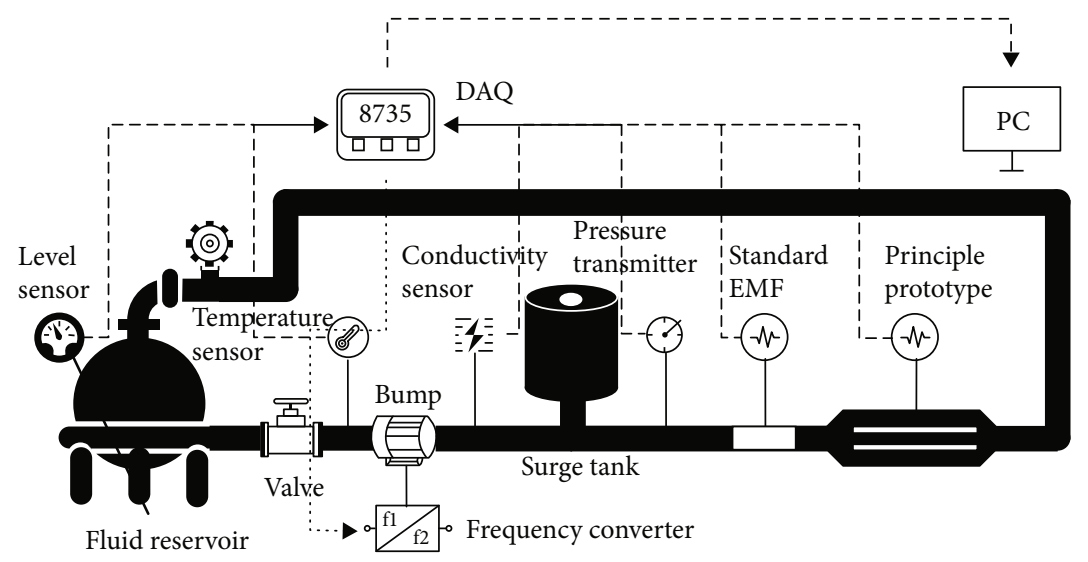

FIgURE 7: The diagram of the annular simulation facility.

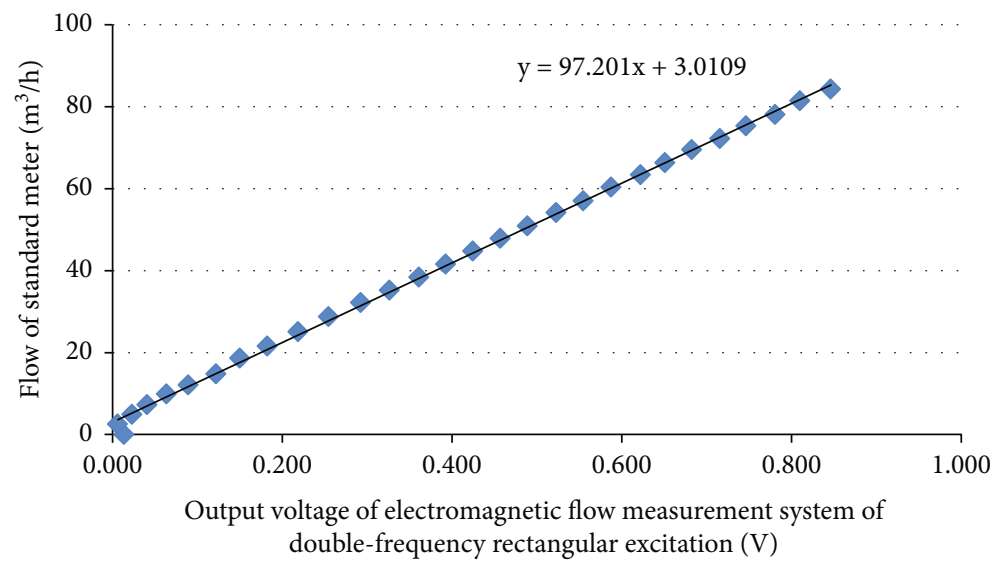

Figure 8: Flow data simulation curve.

Bubble sort is carried out on the demodulation result $\left[\right.$ Awi $(L)^{1}, \operatorname{Awi}(L)^{2}, \cdots$, Awi $\left.(L)^{16}\right]$ by using moving average filtering. The result of the bubble sort is recorded as $\operatorname{Sdr}(L, 1: 16) .8$ data in the middle of the results are taken for averaging as the amplitude in the first period of the electrode output signal under the current highfrequency excitation. The specific result is shown in

$$
\operatorname{Awi}(L)_{[1]}=\sum_{i=4}^{12} \operatorname{Sdr}(L, i) \times \frac{1}{8} .
$$

A complete low-frequency $6.25 \mathrm{~Hz}$ period contains 12 high frequencies of $75 \mathrm{~Hz}$ periods. By amplitude demodulation algorithm, 6 groups of amplitude demodulation results can be obtained in a complete double-frequency excitation period, written as $\left[\operatorname{Awi}(L)_{[1]}, \operatorname{Awi}(L)_{[2]}, \cdots\right.$, Awi $\left.(L)_{[6]}\right]$.

Similarly, the data in 12 complete double-frequency rectangular excitation periods are collected and processed and 72 amplitude demodulation data obtained. Then, 36-point moving average filtering is carried out on the 72 data, which are later processed by bubble sort. Finally, 18 data are taken as the result of amplitude demodulation while averaging, and this demodulation result is served as the accordance of the annular flow calculation.

\section{System Design and Experiment Work}

\subsection{The Laboratory Annular Flow Electromagnetic} Measurement System. Based on previous studies [20-27], the block diagram of the annular flow electromagnetic measurement system using double-frequency excitation was designed, as shown in Figure 6. The system hardware included an electromagnetic flow sensor and electromagnetic sensor converter. The electromagnetic flow sensor was composed of a measurement pipe, excitation coil, and signal electrode. In order to realize digital signal processing, the hardware system of the double-frequency rectangular excitation measurement system was designed with the core of the digital processor. The hardware system module mainly included an excitation driving model, signal preprocessing model, signal modulation model, manmachine interface model, communications model, and power management model.

3.2. Experiment Setup. In order to verify the feasibility of the downhole annular electromagnetic flow measurement principle prototype based on the double-frequency rectangular wave excitation, a flow verification platform for comparison 


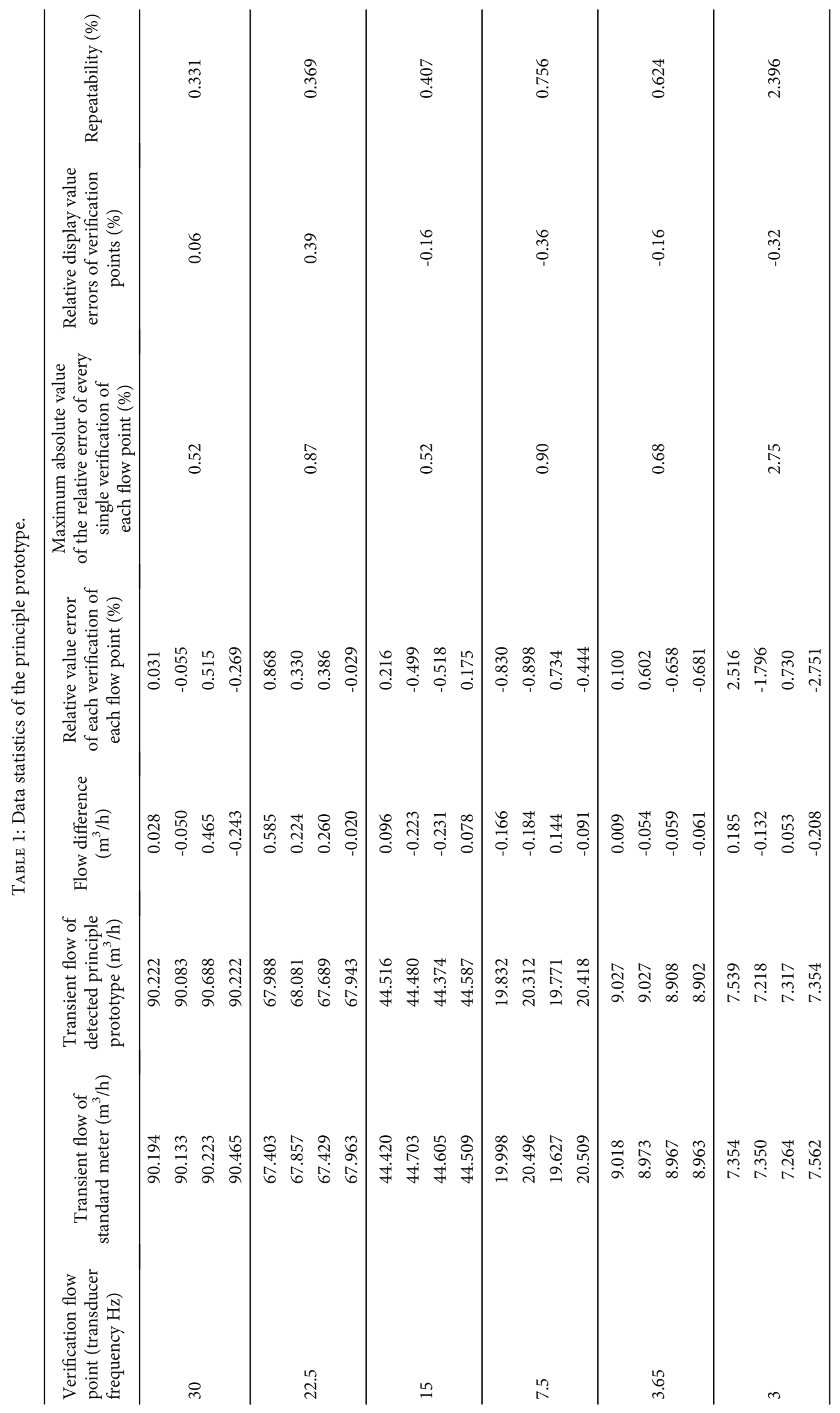




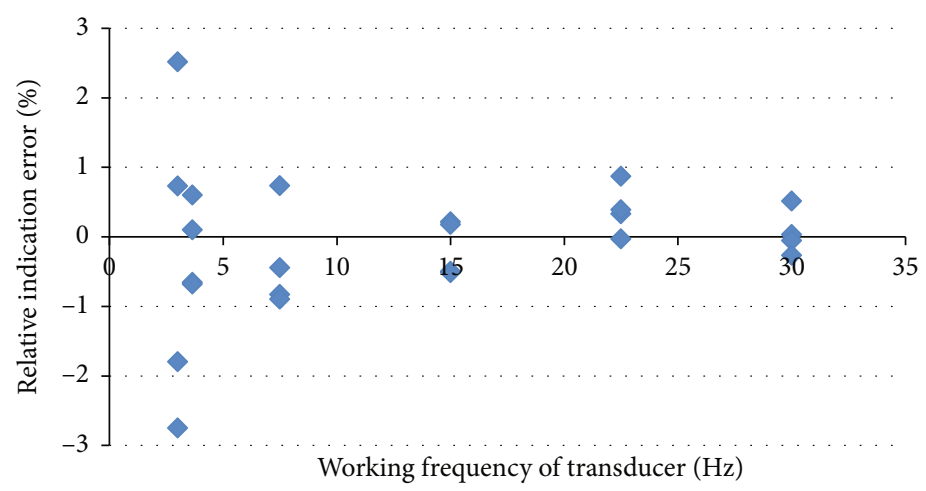

FIGURE 9: Relative indication error distribution of single verification at each flow point.

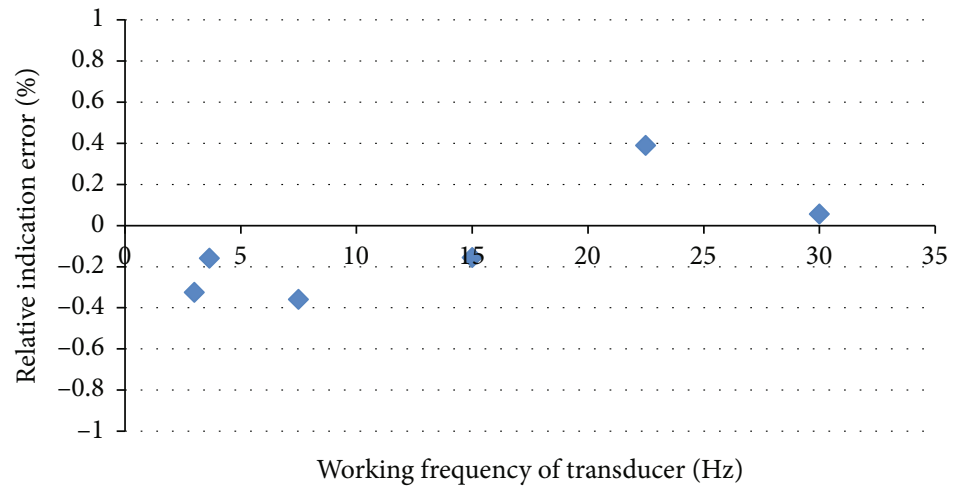

Figure 10: Relative indication error distribution of each flow verification point.

between standard EMF and electromagnetic annular flowmeter measurement system with double-frequency excitation prototype parameters, as shown in Figure 7, was established for simulation experiment. In the experiment, the workflow of the experiment platform is as follows. The principle prototype of ground annular flow electromagnetic measurement system was connected to measurement annular pipelines and a Yokogawa ADMAG AXW electromagnetic flowmeter with an accuracy level of 0.5 was taken as a standard meter. Then, with the valve opened, the transducer started, and the working frequency of the transducer set up, the machine was started at a certain speed under the control of the transducer. The centrifugal pump was driven to work, which pulled out the fluids in the storage tank. The relatively stable fluids driven by the pressure flowed through the standard electromagnetic flowmeter and ground annular electromagnetic measurement system principle prototype in turns. Finally, the fluid flow returned to the storage tank, which formed a whole circulation. In the test, the parameters were obtained by several instruments (thermometer, barometer, conductivity meter, standard flowmeter, and level meter) and the ground annular flow electromagnetic measurement system output annular flow signals, which were later sent to the computers.

3.3. Experiment Design. In order to analyze and determine the performance of the downhole annular electromagnetic flow measurement principle prototype based on the double- frequency rectangular excitation, the standard EMF and principle prototype were connected in series. The fluids flowed through the two devices, and the instrument index, measurement accuracy, repeatability, and other parameters were obtained by reading out the obtained data. In this experiment, the total flow rates of the drilling fluid ranged from $7.2 \mathrm{~m}^{3} / \mathrm{h}$ to $90.1 \mathrm{~m}^{3} / \mathrm{h}$. Data at 6 different flow rates were taken by comparing the standard electromagnetic flowmeter reading to the annular flow electromagnetic measurement prototype.

The principle prototype response of the speed test was designed in order to analyze the sudden change of flow variation caused by the formation of fluid invasion. Then, the sudden change of annular flow channel was realized by controlling the opening level electronically. Finally, the response speeds of the standard meter and principle prototype were analyzed by recording the time relationship of the output data.

In order to verify the priority of the principle prototype in measuring the downhole annular slurry, the effect of the slurry on the principle prototype was analyzed and the slurry test designed. By adding bentonite into clean water, the slurry was obtained, which was tested in this experiment. The flows of the slurry within 1 minute through the standard meter and principle prototype were recorded with a $20 \mathrm{~Hz}$ working frequency of the transducer. At last, the effect of flow media on the standard meter and principle prototype was analyzed. 


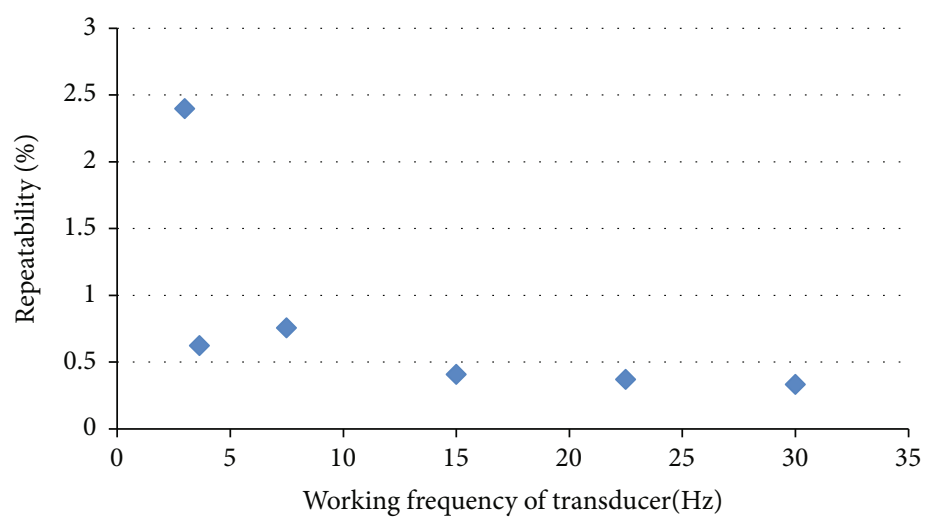

Figure 11: Repeatability distribution of each flow point.

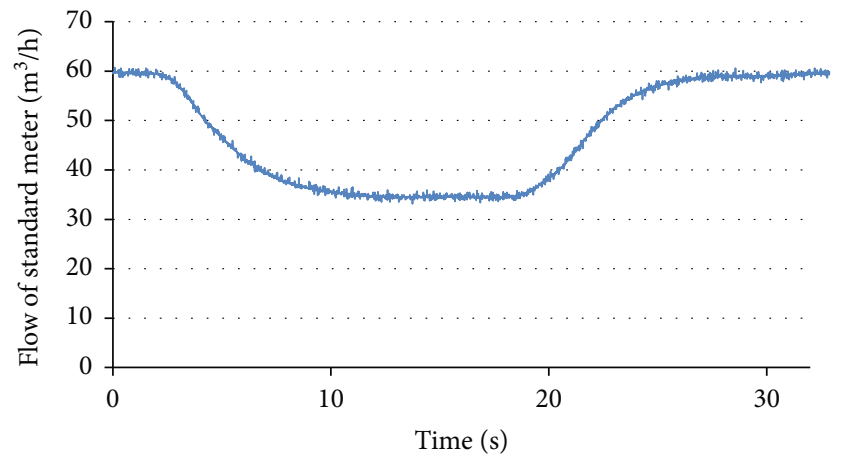

FIGURE 12: Response curve of the standard flowmeter.

\section{Result and Analysis}

4.1. Calibration Results. A clean water flow verification experiment is designed after performing the amplitude demodulation algorithm of the principle prototype, in order to obtain the relationship between the induction electromotive force and the flow. By changing the working frequency of the transducer, the flow of the annular space is realized. After recording the induction electromotive force of two systems, the relationship between the output voltage of the principle prototype and the standard meter is obtained, as shown in Figure 8.

Through curve simulation, the curve equations of a primary curve can be obtained, as shown in

$$
y=97.201 * x+3.0109
$$

where $a=97.201$ and $b=3.0109$, as the instrument coefficient of the principle prototype. According to the experimental analysis, an excellent linear relationship is built between them, which satisfies the measurement principle of the electromagnetic flowmeter.

4.2. System Test Results. In order to obtain the transient flow measurement accuracy of the principle prototype, verification is needed. After correct installation and lining of the electromagnetic flowmeter sensor, the principle prototype is verified according to the rules of verification. The data obtained in the verification is shown in Table 1.

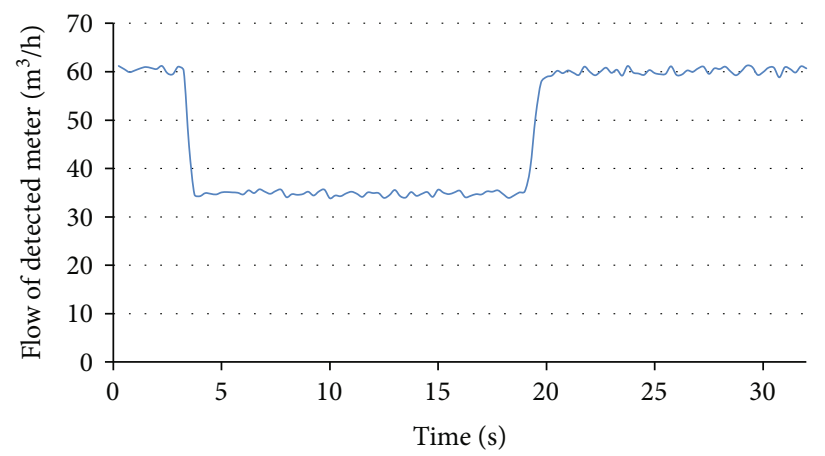

FIGURE 13: Response curve of the principle prototype.

According to the verification rules of the principle prototype, the distribution of the single verification relative value error at each flow point of the principle prototype is shown in Figure 9, and the relative value of each verification point of the principle prototype is shown in Figure 10.

According to the curve, when the flow is lower than $7 \mathrm{~m}^{3} / \mathrm{h}$, that is, flow speed in the pipe is lower than $0.25 \mathrm{~m} / \mathrm{s}$, the relative indicative error is relatively larger, almost more than $1.796 \%$. This problem is similar to the inability of the electromagnetic flowmeter measuring fluid at low speed. The maximum value of another single point indicative error is $-0.898 \%$, while the minimum is $-0.029 \%$. The error of each flow point fluctuates around $0 \%$. The repeatability of each flow point is shown in Figure 11. When the flow speed inside the pipeline is lower than $0.22 \mathrm{~m} / \mathrm{s}$, the repeatability is poor. The repeatability of other points varies around $0.8 \%$. With the increase of the annular flow, the repeatability gets better gradually. According to the data in Table 1, when the flow measurement of the prototype with this signal detection technology ranges within $9-90.1 \mathrm{~m}^{3} / \mathrm{h}$, the relative error of the principle prototype has the maximum of $0.9 \%$, which shows that the transient flow measurement accuracy of the principle prototype is on the 1.0 level.

4.3. Response Speed Test and Analysis. With the butterfly valve adjusted to the half open state, the output data of the standard meter and principle prototype were recorded until the output is stable. Similarly, the butterfly valve was adjusted to be fully open, while recording the output data of the 
TABLE 2: Comparison of response speed.

\begin{tabular}{|c|c|c|c|}
\hline State of butterfly valve & State of flow & Standard EMF & Principle prototype \\
\hline \multirow{2}{*}{ Fully open $\longrightarrow$ half open } & Flow variation $\left(\mathrm{m}^{3} / \mathrm{h}\right)$ & $60 \longrightarrow 34$ & $60 \longrightarrow 34$ \\
\hline & Response time (s) & 7.9 & 4.7 \\
\hline \multirow{2}{*}{ Half open $\longrightarrow$ fully open } & Flow variation $\left(\mathrm{m}^{3} / \mathrm{h}\right)$ & $34 \longrightarrow 60$ & $34 \longrightarrow 60$ \\
\hline & Response time (s) & 7.2 & 4.3 \\
\hline
\end{tabular}
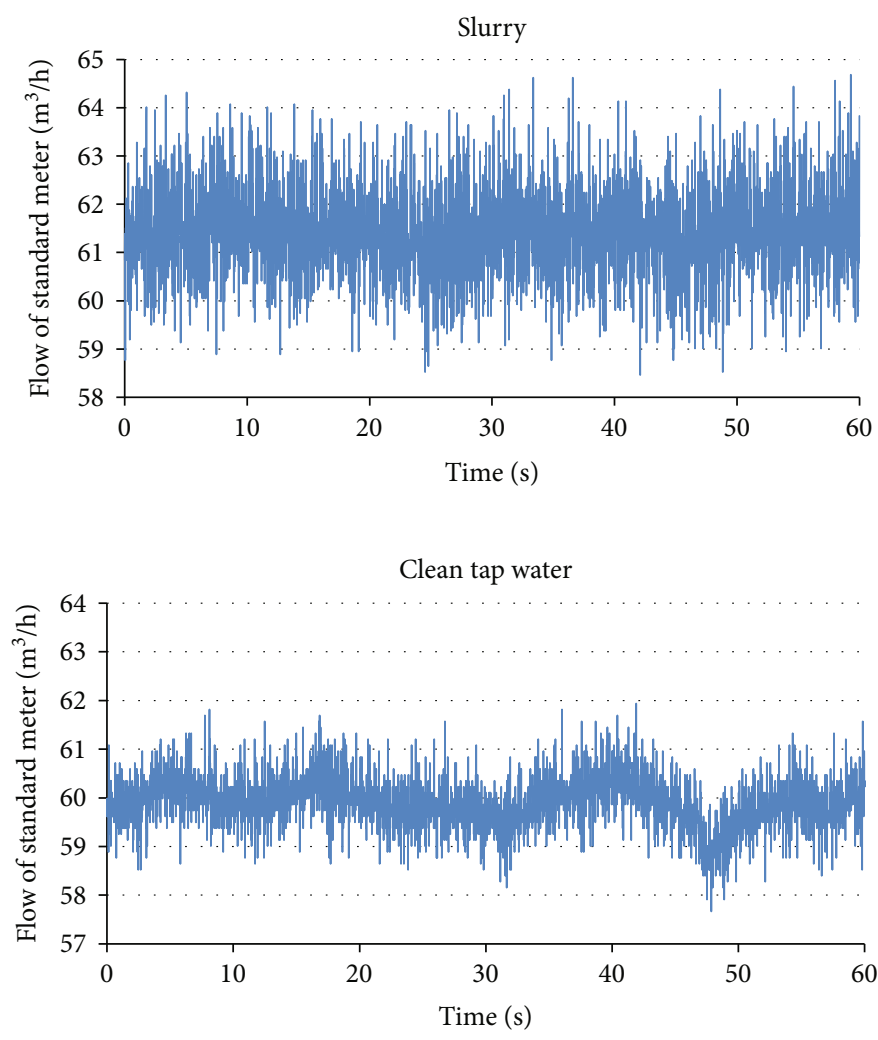

FIGURE 14: Fluctuation rate of the standard meter for different fluids.

standard meter and principle prototype. The response speed of the standard meter and principle prototype can be obtained by the comparison between the two devices.

The flow variation in Figures 12 and 13 and the data in Table 2 illustrate that the response time of the standard flowmeter is $7.9 \mathrm{~s}$ and $7.2 \mathrm{~s}$, respectively, when the valve is adjusted from fully open to half open and half open to fully open. According to Figure 13, the response time of the principle prototype was $4.7 \mathrm{~s}$ and $4.3 \mathrm{~s}$, respectively, when the valve is adjusted from half open to fully open and the other way round. Obviously, the response speed of the principle prototype is better than the standard meter, which can satisfy the demand of rapid overflow detection.

4.4. Influence and Analysis under Slurry Effect. The comparative analysis shows that for the standard meter, as shown in Figure 14, when the measured flow is clean water, the working frequency of the transducer is $20 \mathrm{~Hz}$. The output flow data collected by the standard meter is mainly concentrated within $59-61 \mathrm{~m}^{3} / \mathrm{h}$, without a large fluctuation. When the measured flow is slurry, the fluctuation of standard meter output increases, ranging within $59-64 \mathrm{~m}^{3} / \mathrm{h}$, and is mainly concentrated in $61-62 \mathrm{~m}^{3} / \mathrm{h}$.

The comparative analysis demonstrates that when clean water is under test, the output of the detected meter is mainly concentrated within $59-61 \mathrm{~m}^{3} / \mathrm{h}$ without large fluctuations. When the tested fluid is slurry, the output fluctuation of the detected meter is intensified obviously, in the range of $58-62 \mathrm{~m}^{3} / \mathrm{h}$ and concentrated mainly around $60 \mathrm{~m}^{3} / \mathrm{h}$. According to the comparison between the data collected by the standard meter and detected flow measurement system studied in this paper, when the measured media is water, both flow fluctuations are not large, defined within 59$61 \mathrm{~m}^{3} / \mathrm{h}$. When the slurry is tested, Figures 14 and 15 show that the fluctuation intensity of the standard meter is greater than the electromagnetic flow measurement system with double-frequency rectangular excitation. The conclusion can be drawn that the ability to suppress the slurry interference by double-frequency rectangular excitation is greater than the low-frequency rectangular excitation. 

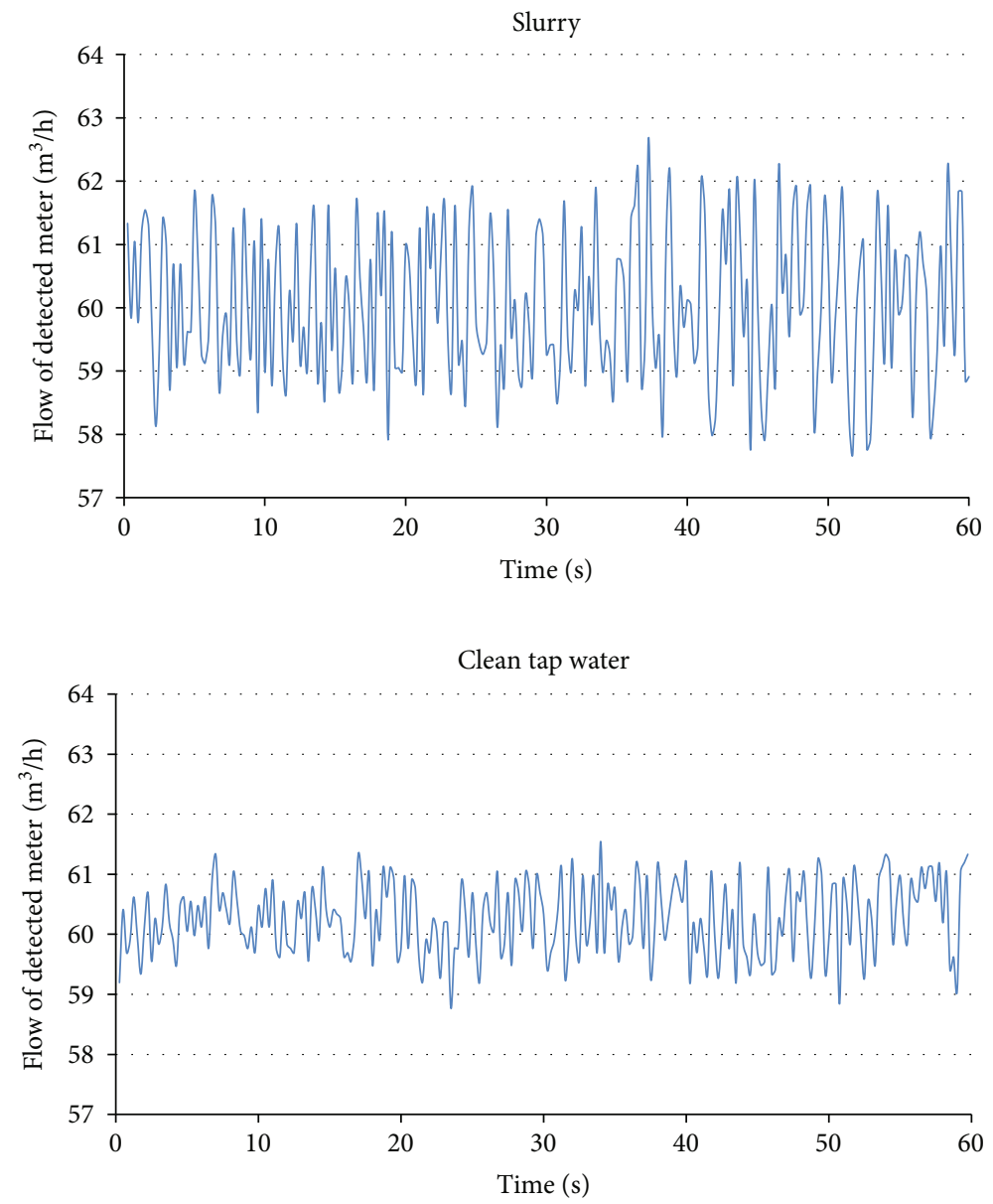

FIGURE 15: Fluctuation rate of the detected meter to different fluids.

\section{Conclusions}

This paper described the downhole annular flow electromagnetic measurement technology based on double-frequency rectangular wave excitation. The conclusions can be drawn as follows:

(1) Aiming at the need of the downhole annular drilling fluid flow measurement, the downhole annular flow electromagnetic measurement principle is analyzed. The double-frequency excitation technology satisfying the need of annular flow electromagnetic measurement is researched and its corresponding electromagnetic induction signal processing investigated

(2) On the basis of previous research, a downhole annular flow electromagnetic measurement system is designed and realized

(3) The flow verification platform of comparison between parameters obtained from standard and detected meters was built for the feasibility test of the electromagnetic flow measurement system with double-frequency excitation. The test results show that the downhole annular electromagnetic flow measurement based on the double-frequency rectan- gular wave excitation can not only satisfy the requirements of regular electromagnetic flow measurement but also suppress the annular slurry interference effectively and meet the needs of rapid overflow detection

\section{Data Availability}

The data sets generated during and/or analyzed during the current study are available from the corresponding author on reasonable request.

\section{Conflicts of Interest}

The authors declare that there is no conflict of interests regarding the publication of this article.

\section{Acknowledgments}

This work is supported by the International Science and Technology Cooperation and Exchange Research Project of Sichuan Province (18GJHZ0195), the Downhole Intelligent Measurement and Control Science and Technology Innovation Team of Southwest Petroleum University (2018CXTD04), and the National Natural Science Foundation (51974273). 


\section{References}

[1] J. Kozicz, "Managed-pressure drilling-recent experience, potential efficiency gains and future opportunities," in IADC/SPE Asia Pacific Drilling Technology Conference and Exhibition, SPE103753-MS, 2006, http://www.onepetro.org/ conference-paper/SPE-103753-MS.

[2] W. Han and M. B. Jean, "Acoustic Doppler downhole fluid flow measurement,” U.S. Patent 6938458, 2005.

[3] W. A. Mark, "Annulus mud flow rate measurement while drilling and use thereof to detect well dysfunction," 2011, U.S. Patent 7950451B2.

[4] J. Wei et al., "Annular measurement device for subsea riser and drill string," China Patent 102174887B, 2011.

[5] L. Shi, P. Chen, Z. Hu, and Y. J. Fu, "The application of bottom-hole flowmeter in the MPD system," Journal of Southwest Petroleum University(Science \&Technology Edition), vol. 32, no. 6, pp. 89-92, 2010.

[6] L. Ge, Z. Hu, P. Chen, L. Shi, Q. Yang, and J. Liao, "Research on overflow monitoring mechanism based on downhole microflow detection," Mathematical Problems in Engineering, vol. 2014, Article ID 676290, 6 pages, 2014.

[7] L. Ge, G. Wei, Q. Wang, Z. Hu, and J. Li, "Novel annular flow electromagnetic measurement system for drilling engineering," IEEE Sensors Journal, vol. 17, no. 18, pp. 5831-5839, 2017.

[8] L. Ge, H. Li, Q. Wang et al., "Design and optimization of annular flow electromagnetic measurement system for drilling engineering," Journal of Sensors, vol. 2018, Article ID 4645878, 12 pages, 2018.

[9] K. Nakamura and F. Wu, "New electromagnetic flowmeter of double-frequency excitation-ADMAG," Foreign Measurment, vol. 1, no. 1, pp. 37-41, 1990.

[10] P. Li, Study and Realization of Slurry Flow Signal Process of Electromagnetic Flow Sensor, Hefei University of Technology, 2014.

[11] Y. Matsunaga, S. Goto, K. Kuromori, and H. Ostling, "New intelligent magnetic flowmeter with dual frequency excitation," Proceedings of Advances in Instrumentation, vol. 43, no. 3, pp. 1259-1267, 1988.

[12] T. Okada, T. Nishijima, Y. Kuroki, and K. Kuromori, "Advanced technology in electromagnetic flowmeters," in ISA Conference, pp. 2079-2094, 1990, https://cc.glgoo.top/scholar?q=Advanced +technology+in+electromagnetic+flowmeters.

[13] I. Wada, "Electromagnetic flowmeter utilizing magnetic fields of a plurality frequencies," U.S. Patent 5090250, 1992.

[14] R. Zhang, K. J. Xv, S. L. Yang, L. P. Liang, G. Wang, and L. Shi, "Electromagnetic flowmeter signal processing system with comb band filtering," Journal of Electronic Measurement and Instrument, vol. 26, no. 2, pp. 177-183, 2012.

[15] T. J. Liu and T. S. Gong, "Design of a time division and double frequency excitation electromagnetic flowmeter," Journal of Sensing Technology, vol. 26, no. 8, pp. 1064-1067, 2013.

[16] L. W. Zhao, Design and Study of Drive Circuit of DoubleFrequency Electromagnetic Flowmeter, University of Yanshan, 2015.

[17] J. A. Shercliff, The theory of electromagnetic flow-measurement, Cambridge University Press, 1987.

[18] M. K. Bevir, "The theory of induced voltage electromagnetic flowmeters," Journal of Fluid Mechanics, vol. 43, no. 3, pp. 577-590, 1970.
[19] D. Han, C. T. Morris, W. Lee, and B. Sarlioglu, "A case study on common mode electromagnetic interference characteristics of GaN HEMT and Si MOSFET power converters for EV/HEVs," IEEE Transactions on Transportation Electrification, vol. 3, no. 1, pp. 168-179, 2017.

[20] Q. P. Liu, X. G. Qiao, J. L. Zhao, Z. A. Jia, H. Gao, and M. Shao, "Novel fiber Bragg grating accelerometer based on diaphragm," IEEE Sensors Journal, vol. 12, no. 10, pp. 30003004, 2012.

[21] C. Stelian, "Calibration of a Lorentz force flowmeter by using numerical modeling," Flow Measurement and Instrumentation, vol. 33, no. 33, pp. 36-44, 2013.

[22] S. Ricci, V. Meacci, B. Birkhofer, and J. Wiklund, "FPGAbased system for in-line measurement of velocity profiles of fluids in industrial pipe flow," IEEE Transactions on Industrial Electronics, vol. 64, no. 5, pp. 3997-4005, 2017.

[23] Y. L. Yeow and J. W. Taylor, "Obtaining the shear rate profile of steady laminar tube flow of newtonian and non-Newtonian fluids from nuclear magnetic resonance imaging and laser Doppler velocimetry data," Journal of Rheology, vol. 46, no. 2, pp. 351-365, 2002.

[24] C. Rosales, M. L. Sanderson, and J. Hemp, "Problems in the theory and design of electromagnetic flowmeters for dielectric liquids. Part 2b: theory of noise generation by charged particles," Flow Measurement and Instrumentation, vol. 13, no. 4, pp. 165-171, 2002.

[25] L. Ge, H. Deng, Q. Wang, Z. Hu, and J. Li, "Study of the influence of temperature on the measurement accuracy of transittime ultrasonic flowmeters," Sensor Review, vol. 39, no. 2, pp. 269-276, 2019.

[26] J. Z. Wang, G. Y. Tian, A. Simm, and G. P. Lucas, "Uniform magnetic flux density simulation and verification for a new electromagnetic flow meter," Nondestructive Testing and Evaluation, vol. 24, no. 1-2, pp. 143-151, 2010.

[27] Y. Wang, H. Li, X. Liu et al., "Novel downhole electromagnetic flowmeter for oil-water two-phase flow in high-water-cut oilproducing wells," Sensors, vol. 16, no. 10, article s16101703, pp. 1703-1719, 2016. 


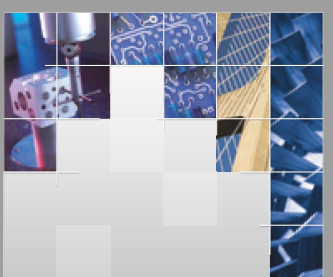

\section{Enfincering}
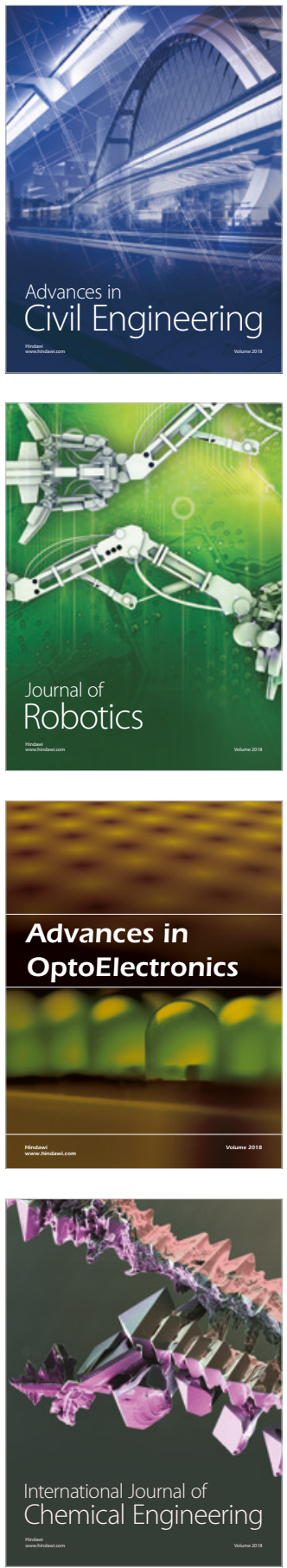

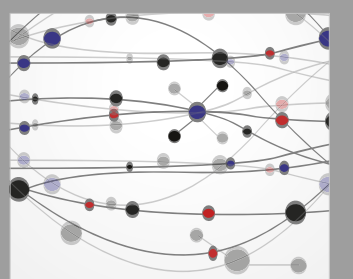

\section{Rotating \\ Machinery}

The Scientific World Journal

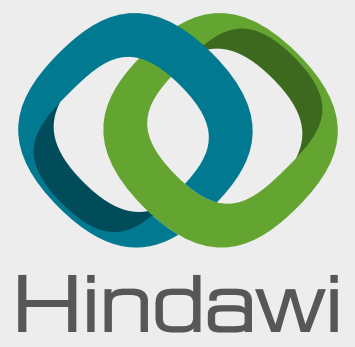

Submit your manuscripts at

www.hindawi.com
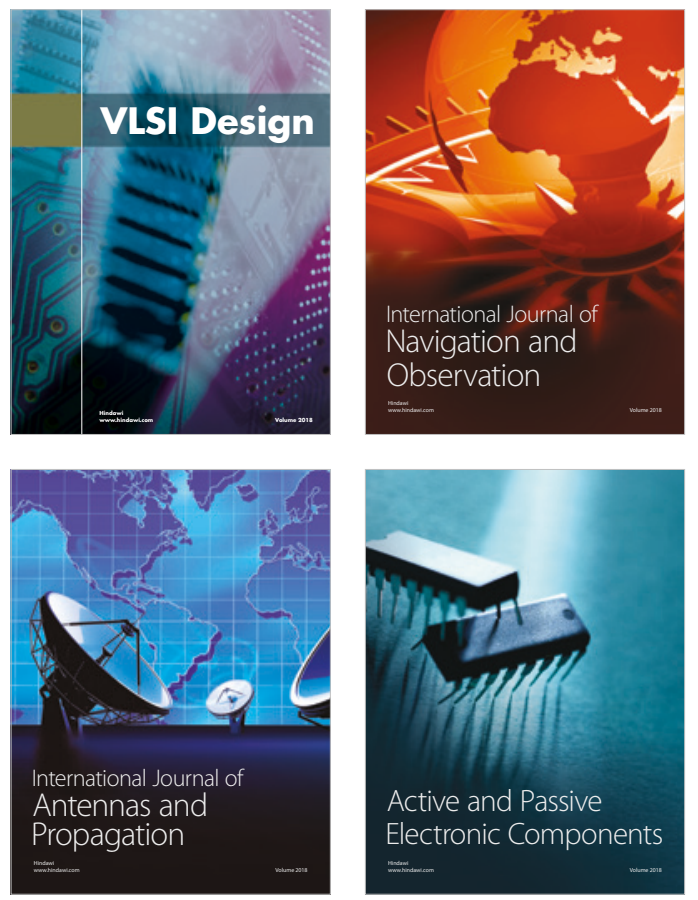
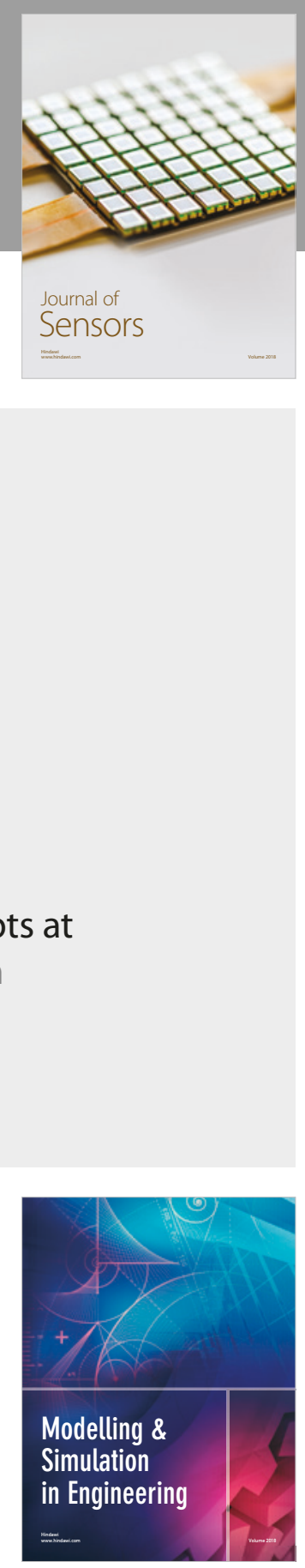

\section{Advances \\ Multimedia}
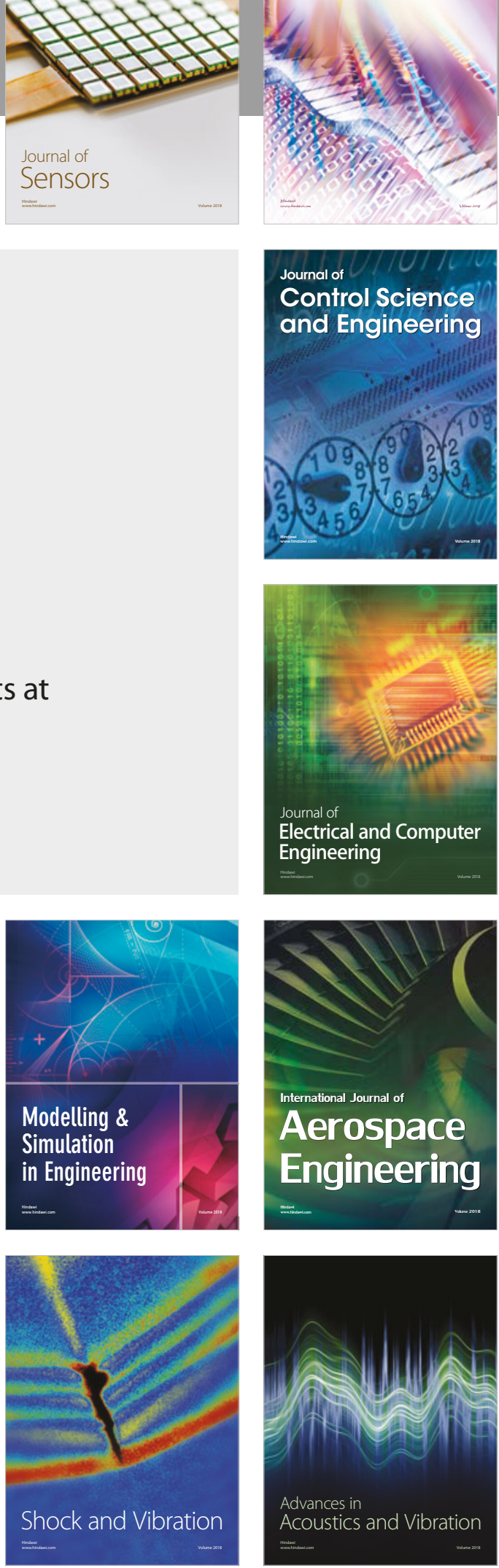